\title{
High-speed compression molding of continuous carbon fiber reinforced polypropylene
}

\author{
S. Enoki ${ }^{1}$, K. Kojima ${ }^{2}$, S. Mizuno ${ }^{2}$, K. Katayama ${ }^{2}$ \& K. Tanaka ${ }^{2}$ \\ ${ }^{1}$ Department of Mechanical Engineering, \\ Nara National College of Technology, Japan \\ ${ }^{2}$ Department of Biomedical Engineering, Doshisha University, Japan
}

\begin{abstract}
Carbon Fiber Reinforced Plastics (CFRP) are expected to be used for car component parts because of their superior mechanical properties and lightweight properties. Automotive lightening is expected by using CFRP for these parts. In addition, considering process time and recyclability, it is desirable to use thermoplastics resin for the matrix. Polypropylene (PP) is a typical thermoplastic and superior material for its low specific gravity, good moldability and low environmental burden, therefore the rate of PP being used has increased remarkably and it is expected to be used for the matrix of CFRP. However, since PP has poor interfacial adhesion to CF, improvement of interfacial properties is necessary. In this study, maleic anhydride-modified polypropylene was used to improve the interfacial adhesion between carbon fiber and matrix resin. Continuous carbon fiber reinforced polypropylene was fabricated by the high-speed compression molding method, and the effect of maleic anhydride-modified polypropylene on the mechanical properties of CFRP was examined. In consequence, the mechanical properties of $\mathrm{CF} / \mathrm{PP}$ were improved by supplying $12.5 \mathrm{wt} \%$ of maleic anhydride modified PP to PP.

Keywords: carbon fiber, polypropylene, maleic anhydride.
\end{abstract}

\section{Introduction}

Carbon Fiber Reinforced Plastics (CFRP) are expected to be used for car component parts because of their superior mechanical and lightweight properties. Automotive lightening is expected by using CFRP. In addition, considering process time and recyclability, thermoplastics resins are desirable to be used for 
the matrix. As polypropylene (PP) is typical thermoplastics and superior material for its low specific gravity, good moldability and low environmental burden, the proportion occupied by PP of total volume of materials for automobiles has reached about $20 \%$ after 2000 [1]. However, since PP does not have a polar group and adhesion to the reinforced fiber is poor, it has not yet been able to take advantage of the strength of the reinforced fibers [2]. As a method for increasing the interfacial adhesion of $\mathrm{CF} / \mathrm{PP}$, maleic anhydride-modified polypropylene (m-PP) having polar groups such as unsaturated carboxylic acid was added to polypropylene (PP) [3]. It is reported in past studies that the strength of the molded specimens increased, with increased interfacial strength between fibers and matrix resins $[4,5]$, when PP becomes to have polarities after m-PP is added to PP [6]. However, in molding of the continuous carbon fiber reinforced polypropylene, the influence of $\mathrm{m}-\mathrm{PP}$ on mechanical properties has not been discussed. In this study, continuous carbon fiber reinforced polypropylene was fabricated by the high-speed compression molding method and the effect of maleic anhydride-modified polypropylene on the mechanical properties of CFRP was examined.

\section{Materials and experimental procedures}

\subsection{Material}

Polypropylene (PP, SA08, Japan Polypropylene Corporation) and maleic anhydride-modified polypropylene (m-PP, Yumex, Sanyo Chemical Industries, LTD.) were used for matrix. They are processed into non-woven fabrics (Kuraray Co, Ltd.) by the melt blown method with weight per unit area at $50 \mathrm{~g} / \mathrm{m}^{2}$ and $9.4 \mathrm{~g} / \mathrm{m}^{2}$ each. As the reinforced fabrics, non-crimp stitched carbon fabric (NCF, $\left.300 \mathrm{~g} / \mathrm{m}^{2},\left[0^{\circ} / 90^{\circ}\right]\right)$, PAN-based carbon fibers being stitched together by polyester sewing thread, were used.

\subsection{Molding method}

Specimens were molded by the high-speed compression molding method [7]. Table 1 shows Melt Flow Rate of PP and m-PP [8]. Table 2 shows the molding conditions: the molding temperature was set at $200^{\circ} \mathrm{C}$ and molding pressure was set at $2 \mathrm{MPa}$. CF/PP-0 shows the case in which the content rate of $\mathrm{m}-\mathrm{PP}$ is $0 \%$; likewise, CF/PP-12.5, CF/PP-25 and CF/PP-100. As for molding of the composite laminates, $\mathrm{NCF}$ and resin non-woven fabrics were laminated so that volume fraction of fiber was $50 \%$ and thickness of the specimens was $2 \mathrm{~mm}$. Temperature history during molding process is shown in Fig. 1. Holding time for maximum temperature of the mold surface at $200^{\circ} \mathrm{C}$ was set for 90 seconds. It took only about 50 seconds to heat up from $50^{\circ} \mathrm{C}$ to $200^{\circ} \mathrm{C}$; the cooling process from $200^{\circ} \mathrm{C}$ to $50^{\circ} \mathrm{C}$ required only about 130 seconds. As a whole, molding was completed in 270 seconds. 
High Performance and Optimum Design of Structures and Materials 313

Table 1: Melt flow rate of PP and M-PP [8].

\begin{tabular}{|c|c|c|}
\hline \multirow{2}{*}{ Temperature $\left({ }^{\circ} \mathrm{C}\right)$} & \multicolumn{2}{|c|}{ MFR(g/10min) } \\
\cline { 2 - 3 } & Polypropylene(PP) & $\begin{array}{c}\text { maleic anhydride-modified } \\
\text { Polypropylene (m-PP) }\end{array}$ \\
\hline 160 & $<0.1$ & 48.4 \\
\hline 180 & 18.9 & $>100$ \\
\hline 200 & 25.1 & \\
\hline 220 & 58.1 & \\
\hline
\end{tabular}

Table 2: Molding conditions of CF/PP.

\begin{tabular}{|c|c|c|c|c|c|}
\hline Specimen & $\begin{array}{l}\text { Content } \\
\text { rate of } \\
\text { m-PP }\end{array}$ & $\begin{array}{l}\text { Temperature } \\
\left({ }^{\circ} \mathrm{C}\right)\end{array}$ & $\begin{array}{c}\text { Pressure } \\
(\mathrm{MPa})\end{array}$ & $\begin{array}{l}\text { Holding time at } \\
\text { maximum } \\
\text { temperature } \\
\text { (s) }\end{array}$ & $\begin{array}{l}\text { Stacking } \\
\text { sequence }\end{array}$ \\
\hline CF/PP-0 & 0 & \multirow{4}{*}{200} & \multirow{4}{*}{2} & \multirow{4}{*}{90} & \multirow{4}{*}{$\begin{array}{c}\operatorname{NCF}\left(0^{\circ} / 90^{\circ}\right)_{3 \mathrm{~s}} \\
\left(300 \mathrm{~g} / \mathrm{m}^{2}\right)\end{array}$} \\
\hline CF/PP-12.5 & 12.5 & & & & \\
\hline CF/PP-25 & 25 & & & & \\
\hline CF/PP-100 & 100 & & & & \\
\hline
\end{tabular}

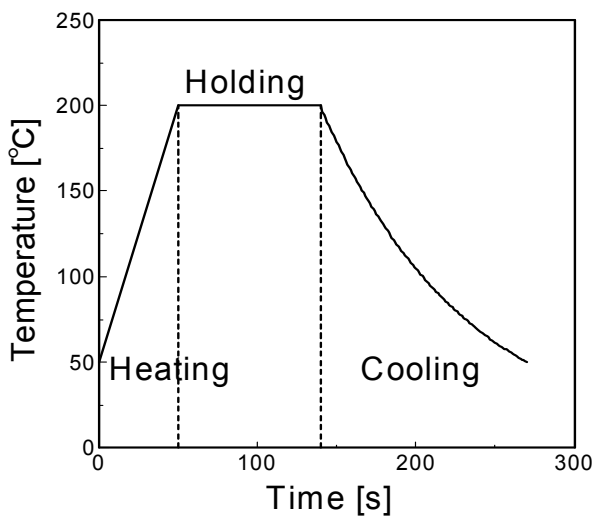

Figure 1: Temperature history of mold surface. 


\subsection{Tensile test}

Tensile test were conducted by using the universal testing machine (Autograph AG-100kN, Shimadzu Corporation) based on JIS-K7164 and displacement rate was set at $1 \mathrm{~mm} / \mathrm{min}$. Aluminium tabs were glued to both ends of specimens in order to mitigate stress concentration and gauge lengths were $70 \mathrm{~mm}$ and $10 \mathrm{~mm}$ in width and $2 \mathrm{~mm}$ in thickness. Extensions between the marked points of the specimen were measured by video-type non-contact extensometer (DVE-201, Shimadzu Corporation).

\section{Results and discussion}

Tensile strength and elastic modulus of CF/PP obtained by tensile test are shown in Figs 2 and 3. CF/PP-12.5 has highest tensile strength. This shows a limit of the potentiating effect for interface adhesive property caused by $\mathrm{m}-\mathrm{PP}$. This is because even if m-PP is added over a definite amount, component of low molecular weight is increased in matrix and tensile strength is decreased [9]. On the other hand, CF/PP-100 has the highest tensile modulus. As shown in Table 1, MFR for maleic anhydride-modified PP is extremely high compared to PP. Due to the flow out of the resin during molding process, actual $V_{f}$ could be higher than the desired $\mathrm{V}_{\mathrm{f}}$ and showing the higher tensile modulus.

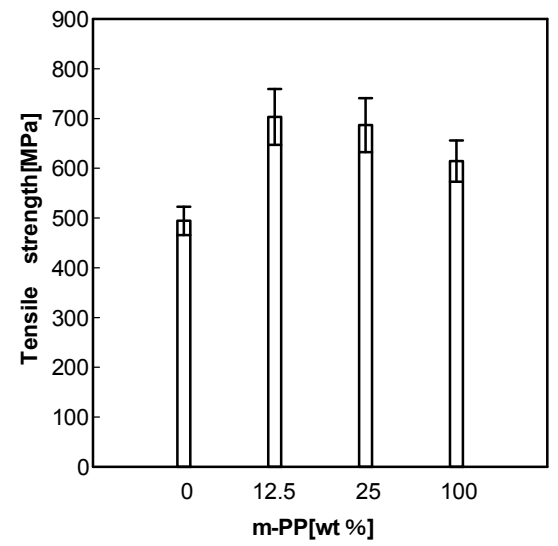

Figure 2: Tensile strength of CF/PP.

\section{Conclusion}

Continuous carbon fiber reinforced polypropylene was fabricated by the high-speed compression molding method and the effect of maleic anhydride-modified polypropylene on the mechanical properties of CFRP was examined. Mechanical properties of CF/PP were improved by sullying $12.5 \mathrm{wt} \%$ of maleic anhydride-modified to PP. 


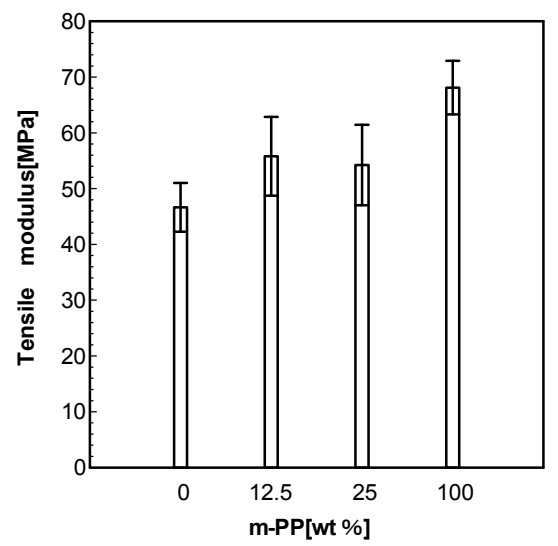

Figure 3: Tensile modulus of CF/PP.

\section{References}

[1] Y. Fujita et al., Development of Polypropylene and Its Application to Automotive parts, Car technology, vol. 63, pp. 16-21, 2009.

[2] L. Yang et al., Temperature dependence of the interfacial shear strength in glass-fibre polypropylene composites, Composites Science and Technology, 71, pp. 1600-1605, 2011.

[3] M. Tamura et al., Improvement of Interfacial property on Carbon Fiber Reinforced Polypropylene, 48th FRP CON-EX, pp. 111-113, 2003.

[4] E. Kristofer et al., Fatigue mechanisms in unidirectional glass-fibre-reinforced polypropylene, Composites Science and Technology, vol. 59, pp. 759-768, 1999.

[5] N. G. Karsli et al., Effects of maleated polypropylene on the morphology, thermal and mechanical properties of short carbon fiber reinforced polypropylene composites, Materials and Design, vol. 32, pp. 4069-4073, 2011.

[6] C. Lin et al., Modification of polypropylene by peroxide-catalysed grafting of maleic anhydride for adhesive bonding: surface and interface, Journal of Materials Science Letters, vol. 12, pp. 612-614, 1993.

[7] K. Tanaka, T. Katayama \& K. Uno, Eco-efficient Manufacturing Process of Fibre Reinforced Thermoplastic, WIT Transactions on the Built Environment, vol. 97, pp. 203-210, 2008.

[8] K. Tanaka et al., Mechanical Property of Glass Continuous Fiber Reinforced Thermoplastics, The 7th Asian-Australasian Conference on Composite Material, pp. 162, 2010.

[9] K. Senthil et al., Mechanical Properties of Injection Molded Long Fiber Polypropylene Composites, Part 1: Tensile and Flexural Properties, Polymer Composites, pp. 259-266, 2007. 